\title{
IMPACT OF A HEAT TREATMENT ON THE MICROSTRUCTURE AND THE LOW CYCLE FATIGUE PROPERTIES OF A 9NI STEEL
}

\author{
${ }^{1}$ Mahira A. COTA ARAUJO, 2Jean-Bernard VOGT, 3 Jérémie BOUQUEREL \\ Univ. Lille, CNRS, INRAE, Centrale Lille, UMR 8207 - UMET - Unité Matériaux et Transformations, Lille, \\ France, ${ }^{1}$ cotaaraujm@univ-lille.fr, ${ }^{2}$ jean-bernard.vogt@centralelille.fr, ${ }^{3}$ jeremie.bouquerel@centralelille.fr.
}

https://doi.org/10.37904/metal.2021.4130

\begin{abstract}
The objective of the present paper is to investigate if the presence and the nature of austenite in 9Ni steel, together with the modification of the matrix induced by heat treatment, change the low cycle fatigue response. The steel was therefore heat-treated so that either a quenched martensitic matrix or a mixture of tempered martensitic with bainitic matrix containing retained or reversed austenite would be obtained, respectively. The experiments showed that while higher stress levels were observed during low cycle fatigue, the quenched microstructure presented a lower fatigue performance under the same applied strain. According to the slip marks pattern, the tempered steel exhibited a higher degree of cyclic deformation accommodation. No obvious effect of austenite in terms of the TRIP effect has been evidenced and the matrix appeared to play a more important role in the fatigue performance. This investigation suggests another possible role of austenite.
\end{abstract}

Keywords: Reversed austenite, retained austenite, martensite, slip marks, fatigue resistance

\section{INTRODUCTION}

$9 \mathrm{Ni}$ steel is low carbon steel widely used as part of liquefied gas storage tanks and pipelines due to the excellent cryogenic toughness. It is well known that a tempering heat treatment must be performed at a lower temperature after quenching to increase the mechanical properties of the material, such as toughness and ductility [2], [4]-[6]. The tempering heat treatment also gives the possibility to obtain the reversed austenite, this phase has a direct impact on the cryogenic toughness of the 9Ni steel [1]-[3]. On the other side, the austenitic phase can be retained after quenching at room temperature due to the segregation of highly gamagenic elements, such as manganese, nickel and carbon. The retained austenite is sometimes undesirable because under some effort, or after subsequent heat treatment, it can transform into a brittle form of martensite, causing premature failure of components.

This study aims to investigate the modification of the microstructure in a 9Ni steel by heat treatment and then study its influence on the low cycle fatigue properties. In particular, attention will be paid to the nature of austenite on the cyclic accommodation and fatigue resistance.

\section{MATERIALS AND EXPERIMENTAL PROCEDURE}

The chemical composition of the investigated $9 \mathrm{Ni}$ steel given by the supplier is (wt \%): $0.04 \mathrm{C}, 8.99 \mathrm{Ni}, 0.53$ $\mathrm{Mn}, 0.23 \mathrm{Si}$. The material has been investigated under two conditions of heat treatment: one set of specimens was submitted to austenitization at $900{ }^{\circ} \mathrm{C}$ for 1 hour and 45 minutes, followed by water quenching. The other set of specimens received the latter heat treatment but was then tempered at $600{ }^{\circ} \mathrm{C}$ for 10 hours.

The austenite content before and after fatigue tests was measured by X-ray diffraction (XRD). The analyses were conducted with the Rigaku Smartlab Diffractometer in a $38-120^{\circ} 2 \Theta$ range by using Cu-ka radiation 
$(\lambda=1.54056 \AA)$. The Cullity method [8] was applied to calculate the amount of the volume fraction of austenite.

The heat-treated specimens were etched in 3\% Nital, and Klemm's II tint etchant was used to reveal the matrix microstructure and the austenitic phase.

Flat low cycle fatigue (LCF) specimens were machined by spark erosion procedure, the dimensions were determined according to the ASTM E606, with a cross-section of $6 \mathrm{~mm} \times 3 \mathrm{~mm}$ and a gauge length of $12 \mathrm{~mm}$. The flat specimens were ground and polished until $1 / 4 \mu \mathrm{m}$ diamond paste and fine-polishing step with Struers OP-U $0.04 \mu \mathrm{m}$ colloidal silica suspension in order to obtain a proper surface for further post-deformation analysis. LCF tests were carried out along the rolling direction of the samples at room temperature at several constant strain ranges $\left(\Delta \varepsilon_{\mathrm{t}}\right.$ (in \%) $=0.8,1.2$, and 1.6) using a triangular waveform with a strain ratio $\mathrm{R}=-1$ and a constant strain rate of $4 \times 0^{-3} \mathrm{~s}^{-1}$. To evaluate the fatigue resistance of the two materials, fatigue life vs plastic strain range was plotted as usual Manson-Coffin correlation to fit the experimental data. Fatigue-induced slip marks were analyzed with a Hitachi S3400N Scanning Electron Microscopy and with an optical microscope, model Countour GT-K 3D (Bruker). The latter had a vertical resolution $<0.1 \mathrm{~nm}$ which allowed quantitative assessment of the roughness of the samples by White Light Interferometry. All the parameters were obtained according to the ISO 25178-2 and ISO 4287 specification standards. Analysis of variance (ANOVA) was used as the analytical tool to interpret the roughness values.

\section{RESULTS AND DISCUSSION}

\subsection{Impact of heat treatments on microstructure}

The selected heat treatments allowed us to obtain a nearly equivalent volume fraction of austenite as indicated by XRD analysis (Figure 1). While the water quenched material contains $8 \%$ of retained austenite, the $10 \mathrm{~h}$ tempered steel contains $11 \%$ of reversed austenite.

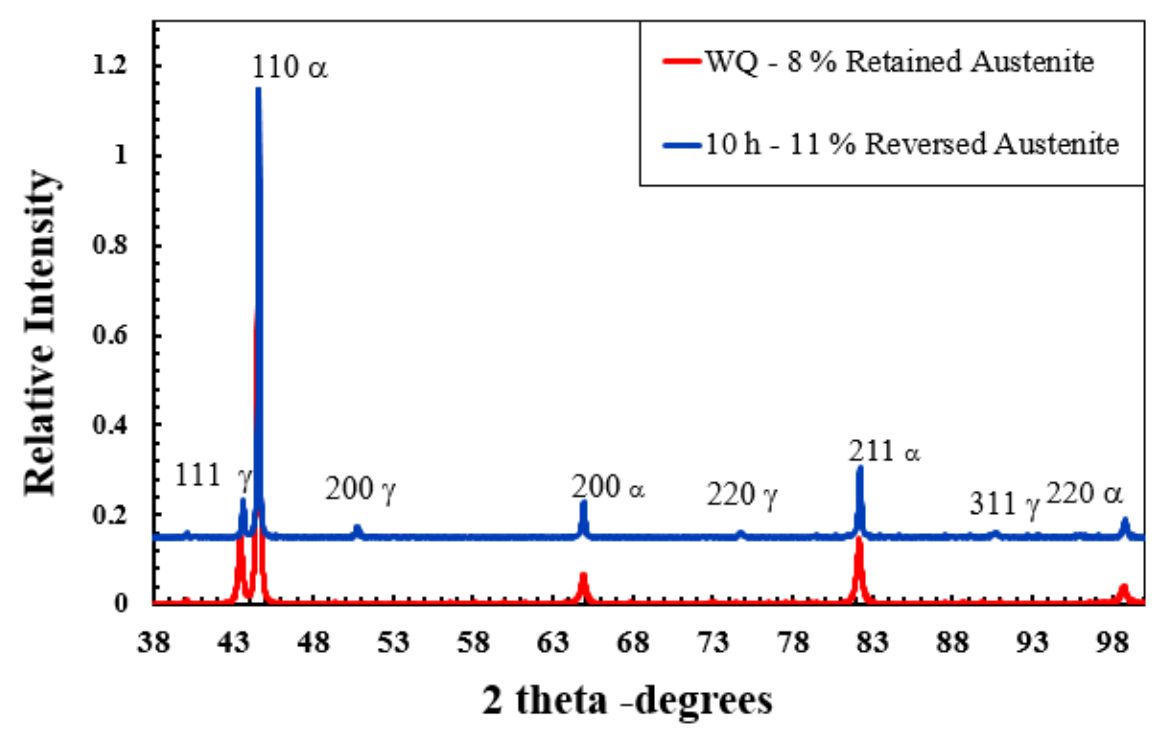

Figure $1 \mathrm{X}$-Ray diffractograms recorded on the quenched steel (WQ) and the $10 \mathrm{~h}$ tempered steel (10h)

However, the heat treatments also affected the matrix and the partition of austenite. The optical micrograph (Figure 2-c) shows a martensitic matrix with some lighter bands of austenite segregated along the rolling direction. The retained austenite is suspected to be present in the form of nanofilms as well, impeding their identification by no other than high-resolution techniques [9]. Figures 2-b and 2-d show the microstructure of the 10 hours tempered steel. It contains both martensite and bainite constituents revealed thanks to Klemm's 
II etchant which coloured bainite in blue and martensite in brown, leaving the austenitic phase unetched. It must be highlighted here again that the austenite detected in the quenched sample is morphologically different from the reversed austenite obtained by tempering heat treatment.

As a consequence, the hardness differs between these materials The Vickers hardness HV10 was 362 for the quenched steel and 237 for the tempered material.
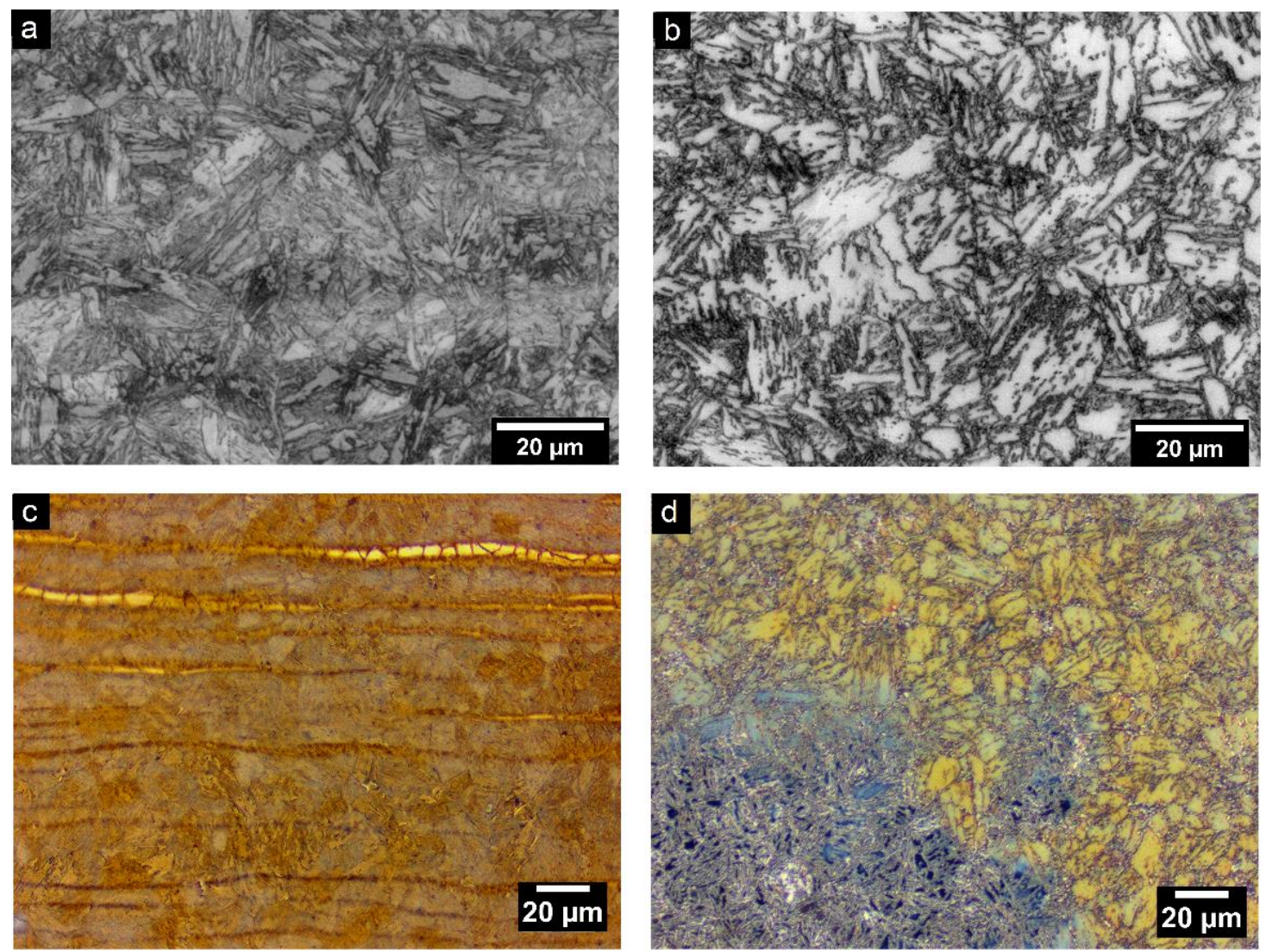

Figure 2 Optical micrographs of the 9Ni steel etched with Nital 3\% (a, b) and Klemm's II solution (c, d): heattreated at $900{ }^{\circ} \mathrm{C}$ and water quenched $(\mathrm{a}, \mathrm{c})$, and 10 hours tempered $(\mathrm{c}, \mathrm{d})$. The yellow/brown zones indicate the martensitic constituent, blue zones correspond to the bainitic constituent and the lighter dots or bands are the austenitic phase.

\subsection{Impact of microstructure on low cycle fatigue behaviour}

Figure 3 shows the evolution of the stress amplitude versus the number of cycles for the tests performed at $\Delta \varepsilon_{\mathrm{t}}($ in $\%)=0.8,1.2$, and 1.6 for each heat-treated material.

For the investigated strain ranges, the peak stress for both steel increases with the applied strain. The stress response to strain cycling is microstructural dependent, especially in terms of stress value. The quenched material exhibits cyclic stress $300 \mathrm{MPa}$ to $400 \mathrm{MPa}$ higher than the tempered steel. Still, both materials start hardening and then softening, the softening rate is much moderate for the tempered which tends to reach stabilization, especially for the higher strain tests. As well, the number of cycles to reach the maximum value of the stress amplitude is smaller for the quenched steel than the tempered one. Such response would appear predictable for the tempered steel if one would ignore the presence of austenite. Indeed, the few cycles related to the cyclic hardening of the tempered steel can be attributed to the release of some dislocations among the numerous entangled and little mobile dislocations produced during the martensitic transformation. Then once dislocation gliding is possible, dislocations annihilation and arrangement towards lower energy configuration 
cause the continuous softening. The same behavior is present for the quenched microstructure, except for the dislocation mobility, once they appear to be more numerous and more tangled.

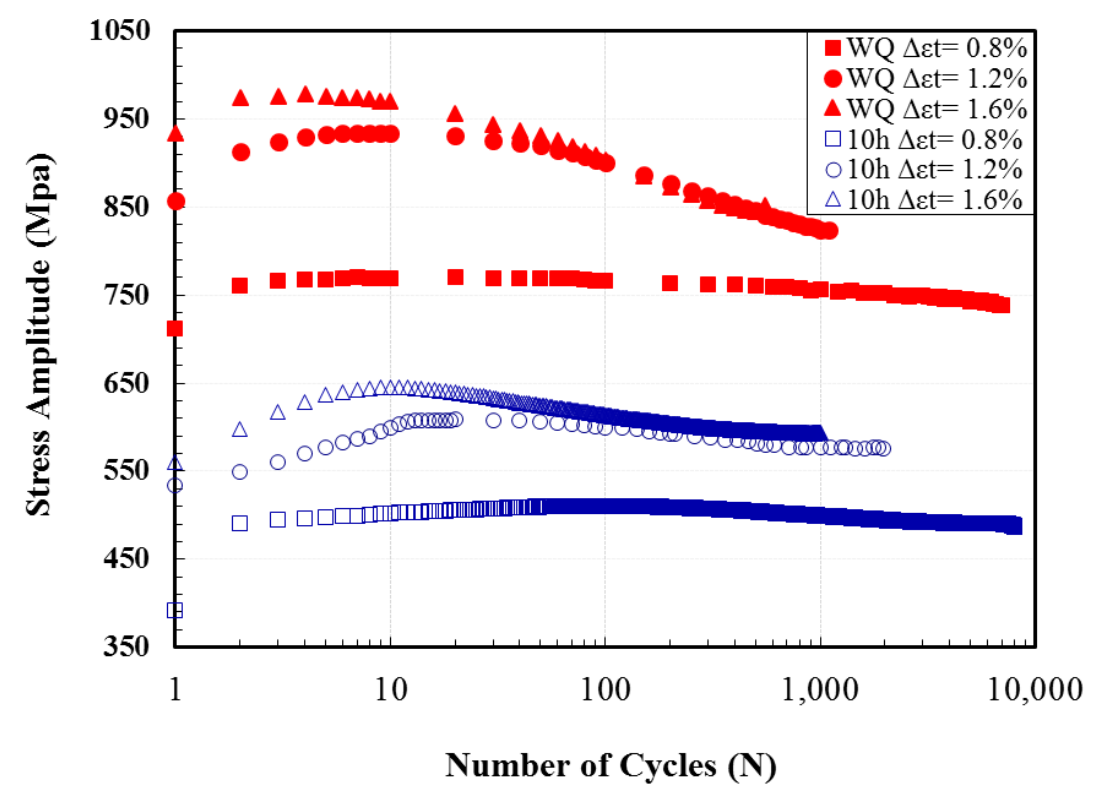

Figure 3 Cyclic accommodation curve for the tests performed at $\Delta \varepsilon_{t}=0.8 \%, 1.2 \%$ and $1.6 \%$ for the quenched $9 \mathrm{Ni}$ steel and the 10 hours tempered $9 \mathrm{Ni}$ steel

Therefore, it turns out that the presence of austenite islands does not seem to play an expected effect in the cyclic accommodation as opposed to what is observed in $12 \mathrm{Cr} 1 \mathrm{MoNbV}$ martensitic steel with the presence of ferrite islands. However, the softer and more stable behavior of the tempered steel sounds well with the effect of the tempering, which partially recovered microstructure, allowing easier initial gliding of dislocations and earlier rearrangement in a more stable configuration. Moreover, the tempered matrix consists of a mixture of bainite and martensite. Yet, tempered bainite is often considered to accommodate plastic deformation [10].

The Manson-Coffin curve for each heat treatment performed in this study is displayed in Figure 4.

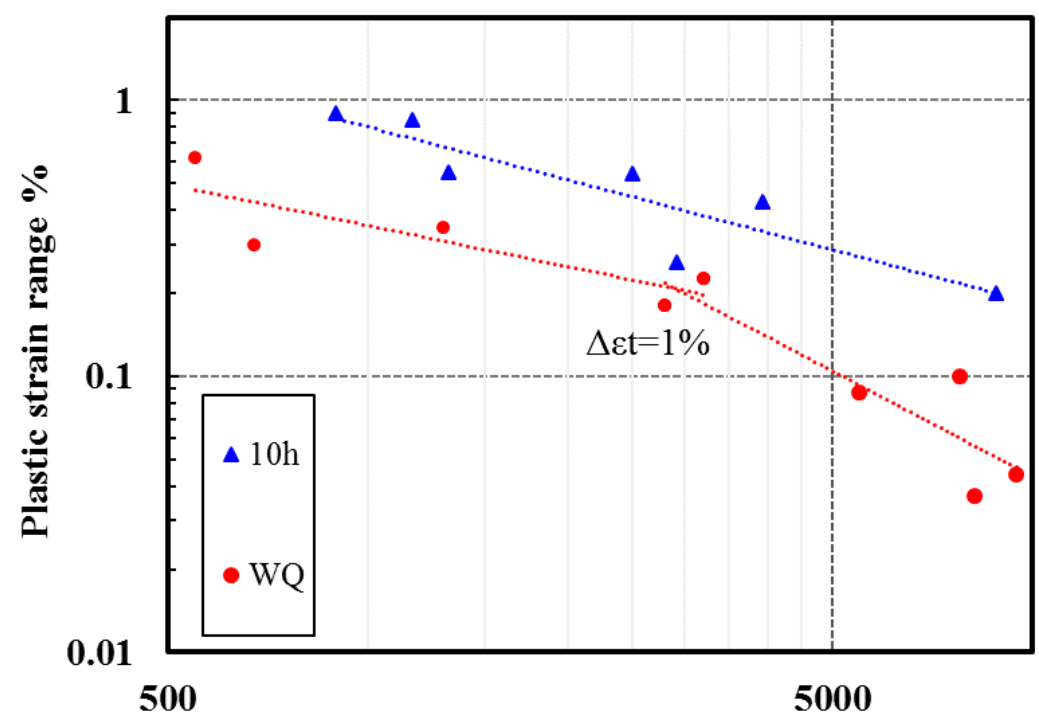

Number of cycles to fracture

Figure 4 Fatigue resistance curve of the quenched $9 \mathrm{Ni}$ steel and the 10 hours tempered $9 \mathrm{Ni}$ steel. 
The logarithmic regression shows that the quenched and tempered samples exhibit a distinct response. The high performance in terms of cyclic stress values of the quenched material is counterbalanced by the low fatigue resistance. Besides, for this material, it was observed a change in the slope at $\Delta \varepsilon_{\mathrm{t}}=1 \%$. Some authors have already reported such a bi-linear behavior for $12 \mathrm{Cr}$ steel, low carbon and bainitic steel [11-12] and this may be linked to the existence of two regimes of fracture mechanism due to the increase in strain levels, and slip system changes.

\subsection{Fatigue slip marks}

The topography of each deformed specimen at $\Delta \varepsilon_{t}=1.2 \%$ as well as the profiles of the surface analyzed by light Interferometry are detailed in Figure 5.

The ability of the tempered steel to accommodate easily the cyclic plasticity is reflected by the numerous slip marks associated with a higher cumulated cyclic strain than the quenched steel (450\% and $714 \%$ ), even if the micrograph is taken at mid-life. Rugosity values were compared using one-way analysis of variance (ANOVA). It was observed a statistically-significant difference between groups of rugosity parameters $(P<$ 0.05), the 10 hours tempered sample showed higher value parameters, confirming the evidence of a highly deformed surface.

It was found that the volume fraction measured after fatigue was slightly decreased to $5 \%$ and $7 \%$ for the quenched and tempered steel, respectively. This indicates that the austenite as well in the retained form as in the reversed one did not play any role through a transformation-induced plasticity mechanism aka the TRIP effect.
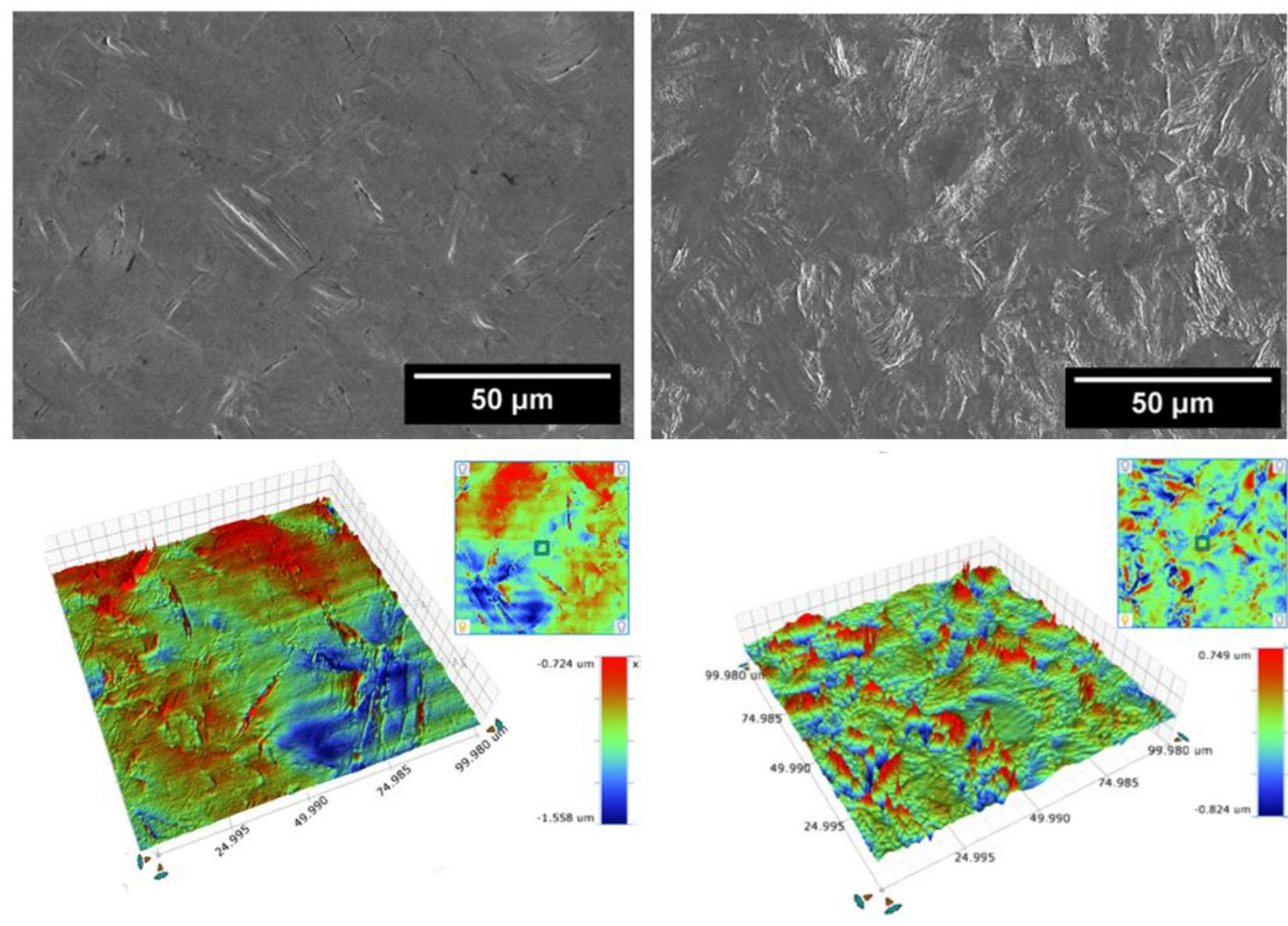

Figure 5 Surface Topography after fatigue up to failure of the quenched $9 \mathrm{Ni}$ steel (left) and at mid-life for the 10 hours tempered $9 \mathrm{Ni}$ steel (right). 


\section{CONCLUSIONS}

A heat treatment allowed producing two materials, which differed in their amount, nature, and location of austenite and matrix (quenched martensite or tempered mixture of bainite and martensite). The experiments showed that while higher stress levels were observed during LCF, the quenched microstructure presented a lower fatigue performance under the same applied strain. According to the slip marks pattern, the tempered steel exhibited a higher degree of cyclic deformation. Regarding the role of austenite, no obvious effect austenite has been evidenced and the matrix appears to play a more important job in the fatigue performance. Nevertheless, this remark is based on assuming a possible effect of austenite in terms of the TRIP effect. Ongoing research tends to suggest that another role of austenite must be considered.

\section{ACKNOWLEDGEMENTS}

\section{The SEM and TEM national facility in Lille (France) is supported by the Conseil Regional des Hauts- de-France and the European Regional Development Fund (ERDF). \\ One of the authors (M. A. C. A). would like to acknowledge the partial financial support of Roberto Rocca Education Program.}

\section{REFERENCES}

[1] WANG, M., LIU, Z.Y., LI, C.G. Correlations of Ni contents, formation of reversed austenite and toughness for Nicontaining cryogenic steel. Acta Metall. Sin. (Engl. Lett.). 2017, vol. 30, pp. 238-249.

[2] ZHANG, J. M.,LI, H., YANG, F., CHI, Q., JI, L. K., FENG, Y. R. Effect of heat treatment process on mechanical properties and microstructure of a 9\% ni steel for large LNG storage tanks. J. Mater. Eng. Perform.. 2013, vol. 22, no. 12, pp. 3867-3871.

[3] ZHAO, X.Q., PAN, T., WANG, Q.F., SU, H., YANG, C.F., YANG, Q.X., ZHANG, Y.Q, Effect of intercritical quenching on reversed austenite formation and cryogenic toughness in QLT-processed 9\% Ni Steel. J. Iron Steel Res. Int.. 2007, vol. 14, pp. 240-2447.

[4] YANG, Y., CAI, Q., WU, H., WANG, H. Formation of reversed austenite and its effect on cryogenic toughness of 9Ni steel during two-phase region heat treatment. Jinshu Xuebao/ Acta Metall. Sin. 2009, vol. 45, pp. $270-274$.

[5] TAVARES, S. S. M., RODRIGUES, C. R. C., de OlIVEIRA, A. S., WOYAMES, C. B., DILLE, J. Influence of heat treatments on microstructure and toughness of 9\%Ni Steel. J. Mater. Eng. Perform. 2018, vol. 27, pp1530-1536.

[6] JIANG, W., ZHAO, K.-Y., YE, D., LI, J., LI, Z.-D., SU, J. Effect of heat treatment on reversed austenite in Cr15 super martensitic stainless steel. J. Iron Steel Res. Int. 2013, vol. 20, pp. 61-65.

[7] KAWATA, H., SAKAMOTO, K., MORITANI, T., MORITO, S., FURUHARA, T., MAKI, T. Crystallography of ausformed upper bainite structure in Fe - 9Ni - C alloys. Mater; Sci. Engn. 2006, vol. 440, pp. 140-144.

[8] CULLITY, B. D. Elements of X-ray Diffraction. Addison-Wesley Publishing, 1956.

[9] MORITO, S., OH-ISHI, K., HONO, K., OHBA, T. Carbon enrichment in retained austenite films in low carbon lath martensite steel. ISIJ Int. 2011, vol. 51, pp. 1200-1202.

[10] JACQUES, P. J., FURNEMONT, Q., LANI, F., PARDOEN, T., DELANNAY, F. Multiscale mechanics of TRIPassisted multiphase steel: I. Characterization and mechanical testing. Acta Mater. 2007, vol. 551, pp. 3681-3693.

[11] VOGT, J.-B., DEGALLAIX, G., FOCT, J. Cyclic mechanical behaviour and microstructure of a 12Cr-Mo-V martensitic steel stainless steel. Fatigue Fract. Eng. Mater. Struct. 1988, vol. 11(6), pp. 435-446.

[12] MARINELLI, M. C., BALBI, M., KRUPP, U. Influence of plastic deformation in fatigue crack behavior in bainitic steel. Int. J. Fatigue. 2021, vol. 143, p. 106014. 